\title{
Development of Ceramics Body using Waste Bone China
}

\author{
Jea-Il Lee, Yong-Seok Lee, and Byung-Ha Lee † $^{\dagger}$
}

Department of Ceramic Engineering, Myongji University, Yongin 449-728, Korea

(Received October 6, 2010; Revised October 20, 2010; Accepted November 2, 2010)

\section{폐본차이나를 활용한 도자기 소지 개발 \\ 이제일 · 이용석 · 이병하 \\ 명지대학교 신소재공학과 \\ (2010년 10월 6일 접수 ; 2010년 10월 20일 수정 ; 2010년 11월 2일 승인)}

\begin{abstract}
The influx of Western culture and the food culture have altered the tableware of Korea, increasing the amount of using tableware. The representative tableware is known as bone china. Considering not only the amount of bone china waste generated from broken tableware at homes and but also faulty bone china products at factories, the bone china waste disposed in simple landfills is to be a serious environmental problem to solve. In this study, following "the research on development of ceramics body using waste celadon" of which the possibility was confirmed, development of ceramics body is conducted by recycling waste bone china. From the result of the study, it was understood that maximum addition of waste bone china was $20 \%$ of the whole material on the basis of measurement of plasticity. So $20 \%$ of pulverized bone china was added and the characteristics were evaluated, and the result was that porosity, water absorptivity and plasticity were $0.756 \%, 0.339 \%$ and $24.13 \%$, respectively. Bending strength was $672 \mathrm{kgf} / \mathrm{cm}^{2}$, which showed a good sintering condition. Therefore, it was considered that waste bone china could be utilized for development of new porcelain material.
\end{abstract}

Key words : Recycling, Waste, Bone china, Ceramics body

\section{1. 서 론}

유럽에서 처음 제조되기 시작한 본차이나는 다양한 서 구식 음식문화의 유입과 더불어 우리나라에서도 그 제조 와 사용이 폭넓게 이루어지고 있다. 이에 의해 사용 중 일상생활에서 사용되다가 파손되어져 버려지고 있는 본 차이나 및 본차이나 제조공장에서 생산 공정 중 결함에 의해 발생되는 본차이나를 감안하면 매년 상당량의 폐도 자기가 발생하고 있는 실정이다. 일부 결함 있는 본차이 나 제품의 경우 조정되어 그대로 사용되는 경우도 있고, 파쇄되어 다시 본차이나 소지 원료로 사용되는 경우도 있 으나, 이렇듯 재활용되는 양은 매우 미미하고, 대부분 단 순 매립에 의해 처리되고 있어 심각한 환경문제로서 대 두되고 있다.

따라서 이러한 세라믹폐기물의 발생에 의한 환경문제를 해결하고자 하는 노력이 이루어지고 있다. 일본과 유럽에 서는 오래전부터 세라믹업체와 관련기관의 기술적인 협조

${ }^{\dagger}$ Corresponding author : Byung-Ha Lee

E-mail : lbh@mju.ac.kr

Tel : +82-31-330-6461 Fax : +82-31-330-6457
와 연구 ${ }^{1-11)}$ 가 진행되고 있으며, 특히 원료의 재활용에 대 한 연구, 기능성 부여에 관한 연구가 활발히 이루어지고 있으나, 우리나라의 경우, 세라믹폐기물에 대한 환경오염 의 저감, 자원의 재활용에 관한 연구는 미미한 상태이다.

이에 본 연구에서는 폐도자기를 이용한 새로운 도자기 소지의 개발 가능성을 확인하였던 지난 “백자 파도자기 를 활용한 도자기 소지 개발 연구"12)와 “청자 파도자기를 활용한 도자기 소지 개발 연구"13)에 이어 국내에서 발생 되어 버려지고 있는 폐본차이나를 도자기소지용 원료로 서 재활용하여 도자기 소지로의 개발을 진행해 보고자 한 다. 이로서 폐본차이나를 사용하여 도자기 소지를 제조함 에 의해 매립에 의해 발생되는 환경 문제를 해결함과 동 시에 자원의 재활용, 특히 일부 수입되어지는 도자기 원 료의 대체원료로서의 활용도 기대되어 경제적 효과도 얻 을 수 있을 것으로 판단된다.

\section{2. 실험방법}

\section{1. 출발 원료}

본 연구에 있어서 소지 조합으로서는 폐본차이나와 국 
Table 1. Chemical Compositions of Raw Materials for Standard Pottery Bodies (wt\%)

\begin{tabular}{cccccccccc}
\hline Materials & $\mathrm{K}_{2} \mathrm{O}$ & $\mathrm{Na}_{2} \mathrm{O}$ & $\mathrm{CaO}$ & $\mathrm{MgO}$ & $\mathrm{TiO}_{2}$ & $\mathrm{Fe}_{2} \mathrm{O}_{3}$ & $\mathrm{Al}_{2} \mathrm{O}_{3}$ & $\mathrm{SiO}_{2}$ & $\mathrm{Ig}$. loss \\
\hline China Clay & 0.6700 & 0.3100 & 0.1200 & 0.1900 & 0.3200 & 0.8300 & 30.4800 & 55.0500 & - \\
\hline NZ-Kaolin & 0.0500 & 0.0600 & 0.0700 & 0.6000 & 0.0800 & 0.2800 & 35.8000 & 52.2000 & - \\
\hline Teabeck Pottery Stone & 1.8617 & 0.1876 & 0.5947 & 0.2515 & 0.0502 & 0.4445 & 14.8607 & 82.9493 & - \\
\hline Buyeo Quartz & 0.0100 & 0.0300 & 0.0200 & 0.0100 & - & 0.0330 & 0.0600 & 99.3600 & - \\
\hline Buyeo Feldspar & 3.7054 & 5.1963 & 0.4248 & 0.0162 & - & 0.0211 & 12.5509 & 77.8674 & - \\
\hline Alumina & - & - & - & - & - & - & 99.657 & - & - \\
\hline
\end{tabular}

Table 2. Chemical Compositions of W.B. (wt \%)

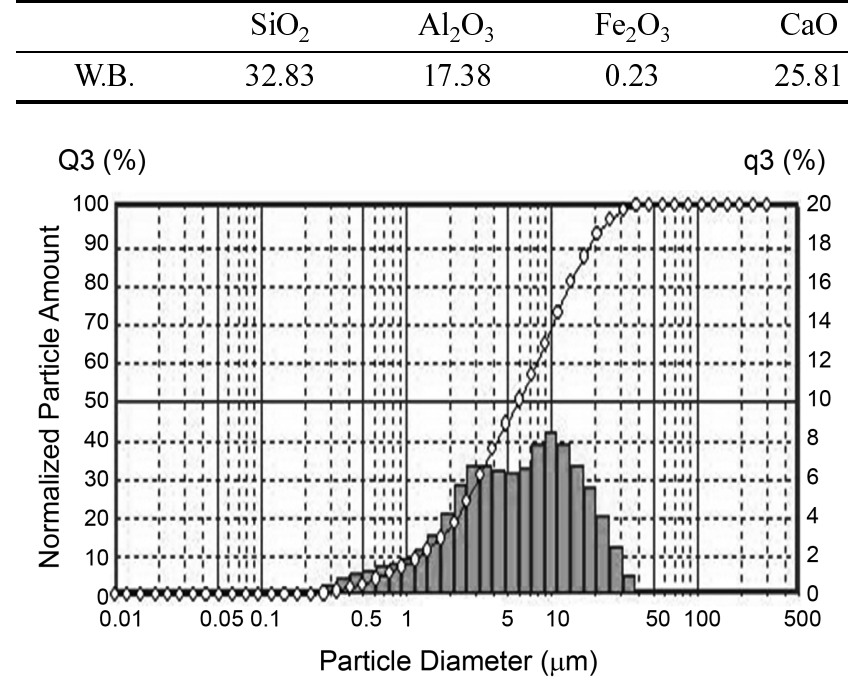

Fig. 1. Particle size distribution analysis of waste W.B after ball-milling.

내에서 시판되고 있는 중국점토, 뉴질랜드카올린, 태백도 석, 부여규석, 부여장석, 알루미나로서 행하였다. 사용되어 진 출발원료에 대한 성분 분석 결과를 Table 1에 나타내었다.

폐본차이나(W.B.: Waste Bone China)는 국내에서 생산 되고 있는 본차이나 제조업체에서 공정상 결함으로 인해 폐기된 폐본차이나를 수거하여 사용하였다. Table 2에 수 거된 폐본차이나의 성분 분석 결과를 나타내었다. 우선 수거된 폐본차이나는 프래트밀(Flat Mill)과 볼밀(Ball Mill) 로서 분쇄하여 $325 \mathrm{mesh}$ 표준체에 전통시켜 미분체로 제 조한 후 소지조합에 첨가하는 실험에 사용하였다. 분쇄된 폐본차이나 분말의 입도분포를 입도분석기(SALD-7101, Shimadzu, Japan)로 확인한 결과, Fig. 1에 보인 바와 같이

\begin{tabular}{ccccc}
$\mathrm{MgO}$ & $\mathrm{K}_{2} \mathrm{O}$ & $\mathrm{Na}_{2} \mathrm{O}$ & $\mathrm{P}_{2} \mathrm{O}_{5}$ & Ig.loss \\
\hline 0.75 & 0.82 & 0.32 & 21.57 & - \\
\hline
\end{tabular}

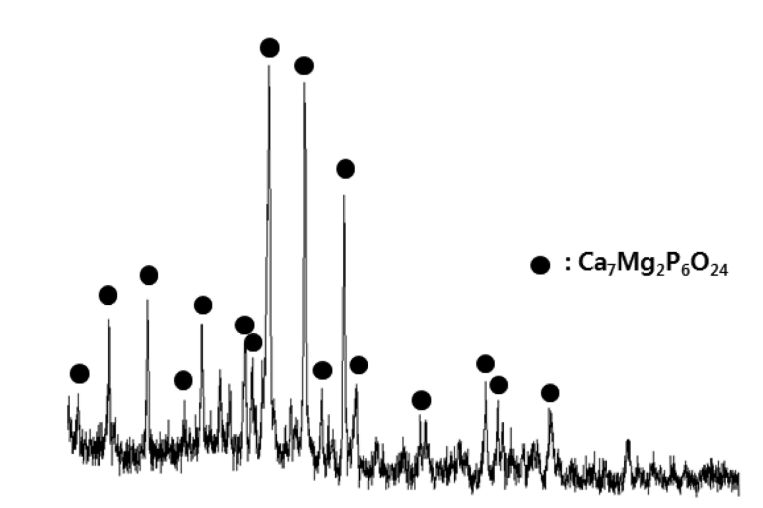

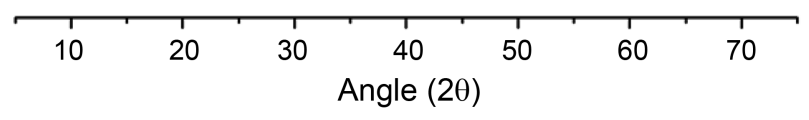

Fig. 2. XRD pattern of waste W.B.

0.4 40 $\mu \mathrm{m}$ 의 입도를 나타내었으며, 이때의 평균입도는 $9 \mu \mathrm{m}$ 였다. 또한 분쇄한 파도자기의 결정상을 확인하기 위해 $\mathrm{X}$ 선 회절분석(XRD-7000, Shimadzu, Japan)을 행한 결과, Fig. 2에서와 같이 주결정상은 $\mathrm{Ca}_{7} \mathrm{Mg}_{2} \mathrm{P}_{6} \mathrm{O}_{24}$ 가 존재하는 것이 관찰되어졌다. 여기에서 관찰된 결정질 뿐만 아니라 첨가되어 있는 유약 등의 유리질 성분이 결정생성 및 성 장에 영향을 미쳐 소결밀도 향상 및 강도증진 등의 물성 측면에서 좋은 결과를 얻을 수 있을 것으로 판단되어, 폐 본차이나 또한 도자기용 원료로서 사용 가능성이 있다고 판단되었다.

본 연구에 있어 조합되어진 조성은 Table 3과 같다.

Table 3. Mineral Compositions of Standard Bone China Bodies (wt \%)

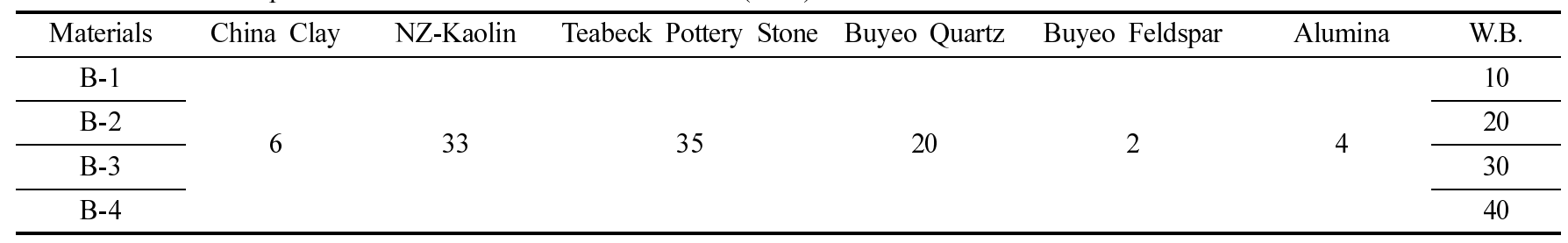




\section{2. 실험 방법}

\subsection{1. 소지 조합}

폐본차이나를 활용한 새로운 소지를 개발하기 위해 기 초실험에서 파본차이나 분쇄분을 $30 \%$ 첨가했을 때, 너무 강한 융제작용이 일어나 기물의 형태 유지가 어려웠던 점 을 확인하고, 소지의 소결온도를 높이기 위해 규석과 알 루미나 양을 증가시키고 장석양은 최소화하였고, 가소성 과 화도를 높이기 위해 뉴질랜드 카올린과 중국점토 양 을 증가시킴에 의해 백색도, 가소성, 하중연화 등 물성조 건을 갖춘 소지 조합의 데이터를 확인하고 이를 기본소 지 조성으로 하여 Table 3 과 같이 폐본차이나 분말을 정 확히 칭량, 혼합하였다. 이후 소지 무게의 $16 ~ 18 \%$ 의 수 분을 가지도록 조정한 후, 7일간 숙성하여 시험편으로 사 용하였다.

\subsection{2. 시편성형}

각 조성의 소지에 대한 물리, 화학적 특성을 측정하기 위하여 석고형을 사용하여 시험편을 제작하였다. 강도 측 정용으로 $6 \times 45 \times 8 \mathrm{~mm}$ 의 막대형(Bar Type), 흡수율 측정 용으로 $\phi 25 \times 4 \mathrm{~mm}$ 의 원주형(Disc Type) 시험편을 성형하 였고, 하중연화 측정용으로 $30 \times 130 \times 8 \mathrm{~mm}$ 의 막대형(Bar Type)의 시험편을 각각 성형하였다.

\subsection{3. 건조 및 소성}

성형한 시험편의 휨이나 갈라짐, 부분건조가 되는 것을 방지하기 위하여 4시간 간격으로 뒤집으며, 7일 동안 자 연 건조시킨 후, 건조기에서 완전 건조를 행하였다. 소성 은 실리코니트 머플가마(Siliconite muffle Furnace)를 사용 하여 상온 $~ 900^{\circ} \mathrm{C}$ 까지는 $5^{\circ} \mathrm{C} / \mathrm{min}, 900^{\circ} \mathrm{C}$ 에서 소성온도인 $1180 \sim 1240^{\circ} \mathrm{C}$ 까지 $3^{\circ} \mathrm{C} / \mathrm{min}$ 로 승온하였다. 이후 1 시간 동 안 유지한 후 자연 냉각하였다.

\section{3. 특성분석}

\subsection{1. 가소성 실험}

가소성은 제품의 성형성과 밀접한 관계가 있는 특성으 로서 제품의 제조에 매우 중요하다. 가소성을 측정하는 방법에는 간접적, 직접적인 방법이 있는데 직접적인 페 펠 케른 법(Pfeffer Korn Method)에 의하면 $1,192 \mathrm{~g}$ 의 철 봉 및 접시를 $186 \mathrm{~mm}$ 의 높이에서 지름 $38 \mathrm{~mm}$, 높이 $40 \mathrm{~mm}$ 의 시험 체 위에 떨어뜨려 최초 시험 체의 높이에 대한 시험 후의 시험 체의 높이 비를 $\mathrm{a}$ 로 하고 $\mathrm{X}$ 축에, 이때의 함수율은 Y축에 표시하여 a가 3.3일 때의 수분량 을 구하여 그 값을 가소성 수치라 하며 수치가 클수록 가소성이 좋다. 실험방법은 지름 $38 \mathrm{~mm}$, 높이 $40 \mathrm{~mm}$ 의 틀에 반죽한 태토를 채워 넣고 밀어내어 시험 체를 만들 고 봉을 떨어뜨린 후 높이를 측정하여 $\mathrm{a}$ 값을 구하여 X 축 그래프에 표시하고, 측정이 끝난 태토는 수분량 측정
을 하여 $\mathrm{Y}$ 축 그래프에 표시한다. 사용했던 태토에 수분 을 추가하여 반죽하고 같은 방법으로 2차, 3차 측정하여 $\mathrm{a}$ 값과 함수율을 측정하여 그래프에 표시하는 방법으로 $\mathrm{a}$ 값이 $\mathrm{X}$ 축 그래프 상 3.3 이상 될 때까지 측정하여 가소 성 수치를 구하였다.

\subsubsection{DT-TG 분석}

각 조성의 소지에 대한 소성온도에 따른 분해, 전이, 새 로운 결정상의 생성 등의 열간 변화를 분석하기 위해 DT$\mathrm{TGA}\left(\mathrm{DTG}-60 \mathrm{H}\right.$, Shimadzu, Japan) 분석을 $1200^{\circ} \mathrm{C}$ 까지 행 하였다.

\subsubsection{SEM 측정}

각 조합비에 따라 소성된 시편의 미세조직을 분석하고 자, 각 소성온도로 소결된 시험편의 파단면을 SEM(SS-550, Shimadzu, Japan)으로 관찰하였다.

\subsection{4. 물성 측정}

도자기 제조용 소지로서 사용되어지기 위해서는 성형 성 뿐만 아니라 소결 후의 특성인 흡수율, 기공률, 강도 등의 특성이 충족되어야 한다. 이에 소성된 시험편의 흡 수율, 기공률, 겉보기비중 측정은 KS L3114에 의해, 수 축률은 KS L4004 측정법을 기준으로 측정하였다. 하중 연화 측정은 소성 시 시험편의 휨 정도를 측정하여 계산하 였으며, 강도 측정은 UTM(MKS Type-PP-650-D, Scientific Instrument, JAPAN)으로서 3점 압축시험법으로 측정하였다.

\section{3. 결과 및 고찰}

\section{1. 가소성 측정}

혼합한 조합에 대한 가소성 측정으로서, 페펠 케른 법 (Pfeffer Korn method)에 의한 측정을 행하고 그 결과를 Fig. 3 에 나타내었다. 그 결과, B- $1: 24.68 \%, \mathrm{~B}-2: 24.13 \%$ B-3 : $23.65 \%$, B-4 : $23.54 \%$ 의 값을 나타내어 파도자기의 첨가량의 증가에 따라 가소성은 조금씩 저하되는 것이 보 여 졌는데, 이는 이미 XRD 분석에서도 보였듯이 폐본차 이나 분쇄분의 주결정상은 가소성이 없는 $\mathrm{CaMg}_{2} \mathrm{PO}_{24}$ 로 이루어져 있어 가소성을 방해하기 때문이라 생각된다.

하지만, 이 값들은 대표적인 가소성원료로 알려져 있는 일본 와목점토의 가소성 측정값은 $36.40 \%$, 뉴질랜드 백 토는 $36.45 \%$, Snow Bone China 소지는 $28.18 \%$, 일반 백자소지가 $26.25 \%$ 정도인 것을 감안하면 낮은 수치를 보였으나, B-2조성까지는 물레성형을 할 경우 제품 성형 에 큰 어려움은 없었다. 그러나 가소성 측정값이 $23 \%$ 이 하인 B-3 이상에서는 물레성형은 어려웠고, 주입성형은 가능하나 B-4 이상에서는 주입성형도 어려운 경향을 보 여 파도자기 첨가량의 한계는 $20 \%$ 라고 판단되었다. 


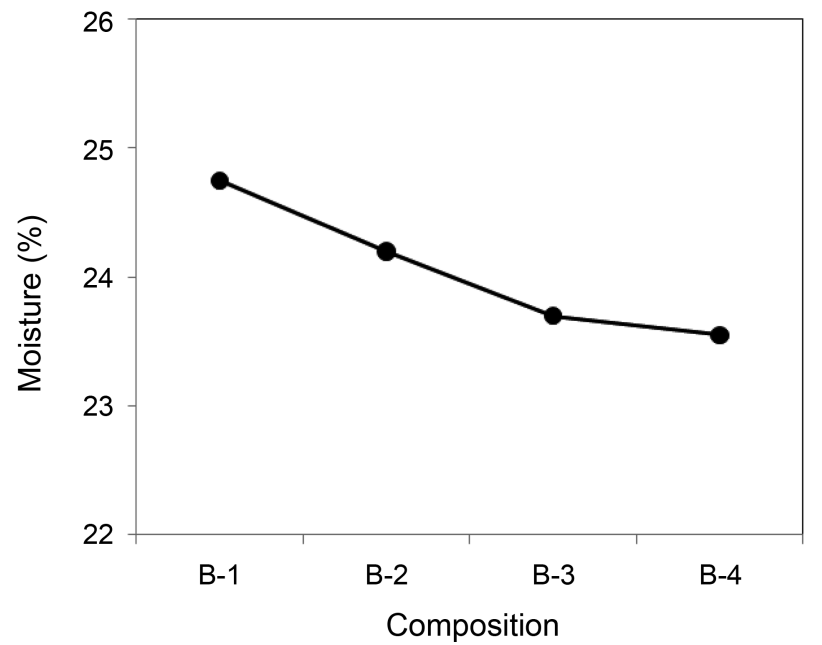

Fig. 3. Result of measurement of plasticity by Pfeffer Korn Method.

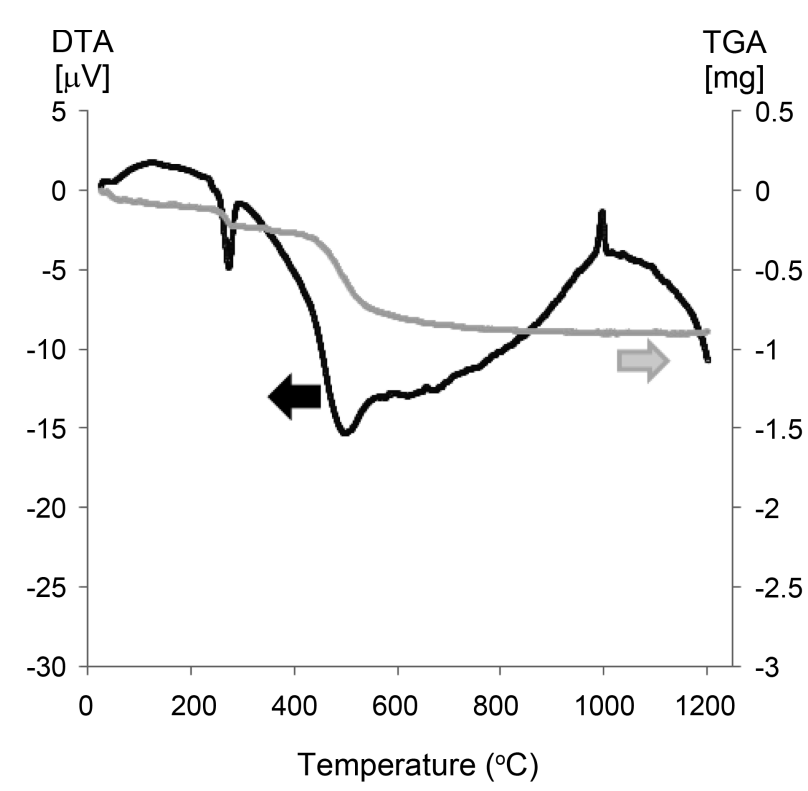

Fig. 4. DT-TG curve of standard bone china body.

\subsection{DT-TG 분석}

폐본차이나가 첨가된 각 조성의 소지의 열간 특성변화를 확인하기 위한 DT-TG 분석을 행하고, 그 결과 중 B-2의 결 과를 Fig. 4에 나타내었다. 이 결과에서 보이는 바와 같이 $220^{\circ} \mathrm{C}$ 와 $450^{\circ} \mathrm{C}$ 부근에서 수분의 증발과 유기물 등의 분해 에 의한 것으로 보이는 피크와 중량감소가 확인되었으며 $1000^{\circ} \mathrm{C}$ 부근에서는 폐본차이나를 첨가한 기본소지 내부에 서의 뮬라이트의 생성으로 보여지는 피크가 관찰되어져 도 자기 소지로서의 합성이 이루어지고 있음이 관찰되었다.

\section{3. 물성 측정 분석}

3.3.1. 도자기 소지로서의 기본 물성의 측정

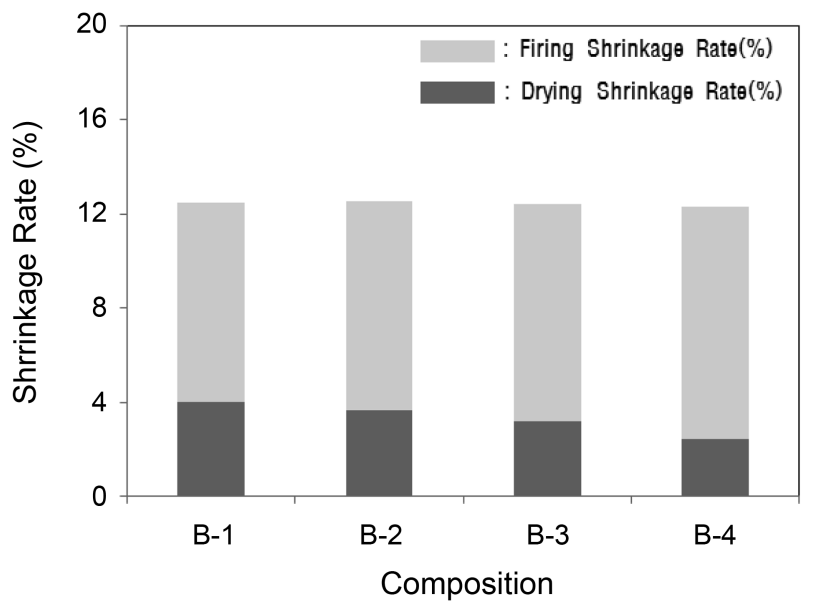

Fig. 5. Drying shrinkage rate and firing shrinkage rate of each compositions.

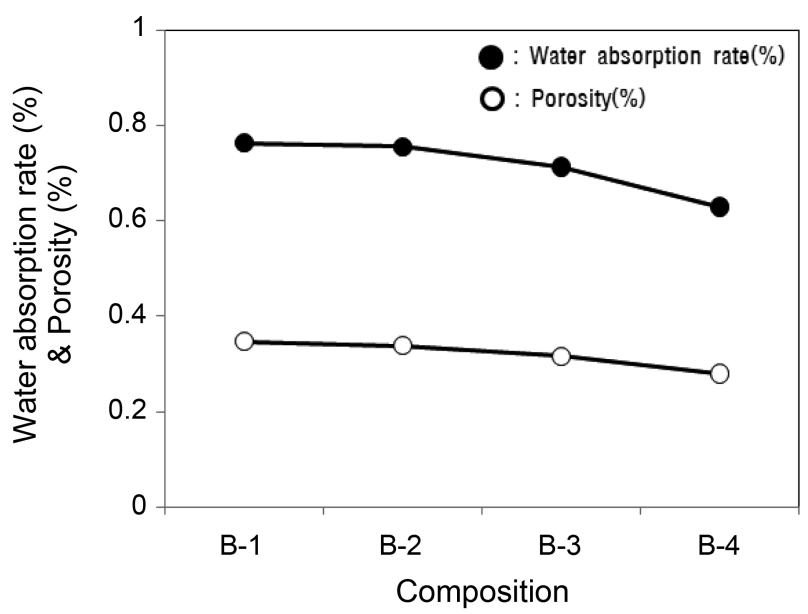

Fig. 6. Porosity and water absorption rate of each compositions sintered at $1200^{\circ} \mathrm{C}$.

Table 3 의 조성과 같이 기본소지에 폐본차이나 분쇄분 을 첨가한 후, 건조수축율과 소성수축률을 측정하고, 그 결과를 Fig. 5에 나타내었다. 건조수축률은 앞서 측정한 가소수량의 결과에서와 같이 수분포함함량이 많은 B-1로 부터 B-4로 첨가량의 증가에 따라 감소하는 경향을 나타 내었다. 하지만, 각 조성의 소지를 $1200^{\circ} \mathrm{C}$ 로 소성한 후 측 정한 소성수축률 결과에 있어서는 건조수축율과 반대로 B-1로부터 B-4로 폐본차이나 소지의 첨가량 증가에 따라 오히려 증가하는 경향을 보였다. 이는 폐본차이나 소지 속에 들어있던 알카리토류 성분과 $\mathrm{P}_{2} \mathrm{O}_{5}$ 의 증가에 의한 매 용 작용으로 소결온도의 차이가 발생하고, 그에 따라 일 부 과소성이 일어나는 것이다.

다음으로 각 조성의 소지를 $1200^{\circ} \mathrm{C}$ 로 소성한 후, 기공 률과 흡수율을 측정하여 그 결과를 Fig. 6에 나타내었다. 기공률의 경우, B-1:0.764\%에서 B-4:0.630\%로, 흡수율 


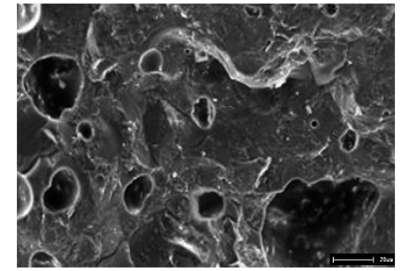

(a) B1

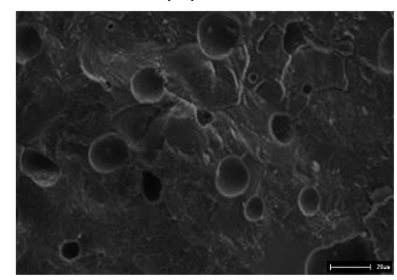

(c) B3

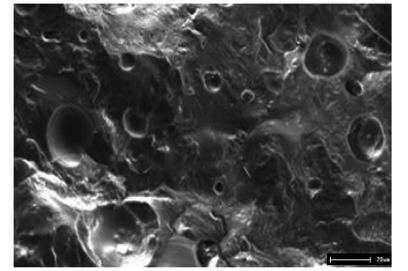

(b) B2

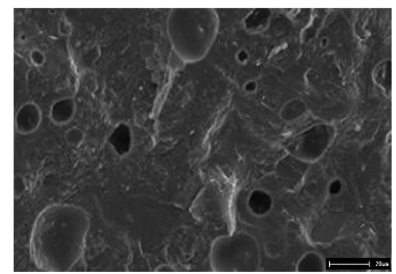

(d) B4
Fig. 7. SEM photographs of each compositions sintered at $1200^{\circ} \mathrm{C}$.

의 경우에도 B- $1: 0.347 \%$ 로부터 B- $4: 0.28 \%$ 로 수축율의 평가에서와 같은 이유에 의해 폐본차이나 분말 첨가량의 증가에 따라 감소하는 경향을 나타내었다.

\subsubsection{SEM 분석}

기공률 및 흡수율의 변화에 대한 이유를 확인해 보고 자, $1200^{\circ} \mathrm{C}$ 로 소성한 시험편의 미세구조를 관찰하고, 그 결과를 Fig. 7에 나타내었다. 다수 기공들이 관찰되어지 던 $\mathrm{B}-1$ 에서부터 폐본차이나 첨가량이 증가함에 따라 큰 변화는 없었으나 폐본차이나 분쇄분이 $40 \%$ 첨가된 $\mathrm{B}-4$ 에서는 기공이 감소하였다. 소지 상태에서는 소결이 진행 되어서 과 소성되어 지고 있다.

\subsection{3. 굽힘강도 및 하중 연화}

다음으로 $1200^{\circ} \mathrm{C}$ 로 소성한 각 조성에 대해 굽힘강도 측 정을 행하고 그 결과를 Fig. 8에 나타내었다. B-1 조성의 굽힘강도값은 $656 \mathrm{kgf} / \mathrm{cm}^{2}$ 를 나타내었고, B-2 조성은 $672 \mathrm{kgf} / \mathrm{cm}^{2}$ 으로서 본 실험범위에서는 가장 높은 강도값 을 보였다. 이후 $30 \%$ 이상의 폐본차이나가 들어간 B-3와 B-4 조성에서는 각각 $660 \mathrm{kgf} / \mathrm{cm}^{2}, 635 \mathrm{kgf} / \mathrm{cm}^{2}$ 으로 측정 되어 앞서 측정한 물성평가 결과에서와 같이 유리상의 증 가가 강도의 저하에 기인한 것이라 판단되었다.

Fig. 9는 $1180 \sim 1240^{\circ} \mathrm{C}$ 의 온도에서 각각 소성한 시편에 대해 하중연화 측정을 행하고, 그 측정 결과를 나타낸 것 으로서, 일반적으로 $4 \sim 6 \mathrm{~mm}$ 정도의 변형률을 가진 소지 까지는 제품 생산이 가능하다는 점을 감안하면, $1200^{\circ} \mathrm{C}$ 소성의 B-2의 경우 $3.8 \mathrm{~mm}$ 의 변형률로 충분히 도자기 생 산에 적용 가능하다고 할 수 있다. 또한 $1200^{\circ} \mathrm{C}$ 의 B-3와 $1220^{\circ} \mathrm{C}$ 의 B-2까지도 사용 가능한 변형수치로 나타났다. 따라서, 도자기로서 적용 가능한 하중연화 측정치를 나타 낸 폐본차이나 첨가 소지를 이용하면, 기물의 변형이 적

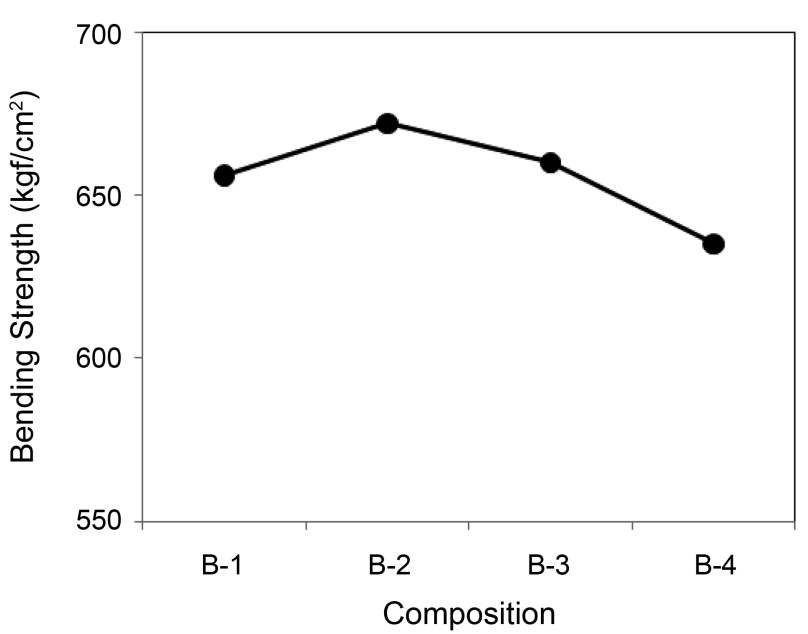

Fig. 8. Bending strength of each compositions sintered at $1200^{\circ} \mathrm{C}$.

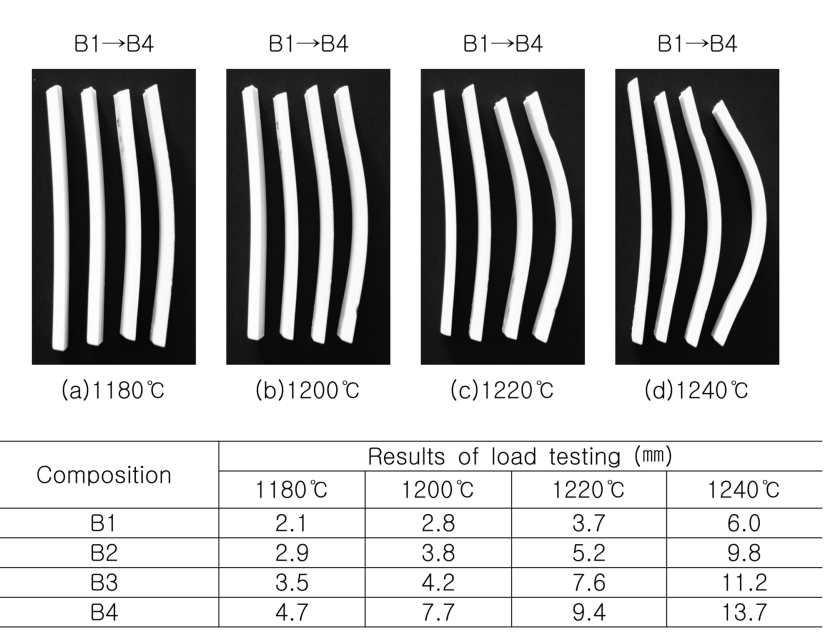

Fig. 9. Result of load testing of each compositions at various temperature.

어, 직접 소성에 의한 가마재임에서의 공간 활용의 효율 성을 높일 수 있고, 불량률의 저하 및 소성온도를 낮추어 에너지 절약할 수 있다는 등의 장점이 있어, 폭넓은 활용 을 기대할 수 있을 것으로 생각된다.

\section{4. 결 론}

폐본차이나 분쇄분을 사용하여 새로운 재활용 도자기 소지의 개발에 대한 실험 결과, 다음과 같은 결과를 얻었다.

(1) 본 실험범위에 있어, 폐본차이나가 첨가된 전 조성 에 걸쳐서 기존 본소지의 소성온도 보다 낮은 온도영역 인 $1200^{\circ} \mathrm{C}$ 영역에서 소성이 가능하였다. 이는 폐본차이나 분쇄분 중에 포함되어 있는 유약성분과 폐본차이나의 $\mathrm{CaO}$ 와 $\mathrm{P}_{2} \mathrm{O}_{5}$ 성분으로 인하여 소성 시 온도를 낮추는 역할을 하였기 때문이다. 
(2) 본 실험범위에 있어, 폐본차이나 분쇄분을 이용한 새로운 도자기 소지로서의 활용을 위한 가소성 측정에서 의 첨가 한계는 $20 \%$ 라고 판단되었다. 이 폐본차이나 분 쇄분이 $20 \%$ 첨가된 B-2 소지의 경우, $1200^{\circ} \mathrm{C}$ 로 소결한 시험편의 물성 측정 결과에서도, 기공률은 $0.756 \%$, 흡수 율은 $0.339 \%$ 로 양호한 값을 나타내었으며, 굽힘강도 값 도 $672 \mathrm{kgf} / \mathrm{cm}^{2}$ 로서 높은 값을 보였다.

(3) 도자기용 원료로서 폐본차이나 분쇄분을 리사이클 링 함으로서, 제조원가 절감 등의 경제적 효과를 얻을 수 있을 뿐만 아니라 환경오염 문제의 해결을 이룰 수 있는 새로운 도자기 소지로서의 활용이 기대되어진다.

\section{REFERENCES}

1. F. Andreola, L. Barbieri, A. Corradi, I. Lancellotti, and T. Manfredini, "Utilisation of Municipal Incinerator Grate Slag for Manufacturing Porcelainized Stoneware Tiles Manufacturing," J. Eur. Ceram. Soc., 22 [9-10] 1457-62 (2002).

2. I. Agote, A. Odriozola, N. Gutierrez, A. Santamaria, J. Quintanilla, P. Coupelle, and J. Soares, "Rheological Study of Waste Porcelain Feedstocks for Injection Moulding," J. Eur. Ceram. Soc., 21 [16] 2843-53 (2001).

3. R. R. Menezes, H. G Malzac Neto, L. N. L. Santana, H. L. Lira, H. S. Ferreira, and G. A. Neves, "Optimization of Wastes Content in Ceramic Tiles using Statistical Design of Mixture Experiments," J. Eur. Ceram. Soc., 28 [16] 3027-39 (2008).

4. R. R. Menezes, H. S. Ferreira, G. A. Neves, H. L. Lira, and H. C. Ferreira, "Use of Granite Sawing Wastes in the Production of Ceramic Bricks and Tiles," J. Eur. Ceram. Soc., 25 [7] 1149-58 (2005).

5. F. A. C. Oliveira, V. Livramento, and F. Delmas, "Novel
Mullite-Based Ceramics Manufactured from Inorganic Wastes. I. Densification Behaviour," J. Mater. Process. Tech., 196 [1-3] 101-8 (2008).

6. J. O. Hong, S. G. Kang, K. G. Lee, Y. T. Kim, Y. J. Kim, J. H. Kim, and M. S. Park, "Characteristics of Sintered Bodies Made from the System of Paper Sludge Ash-Fly AshClay(in Korean)," J. Kor. Ceram. Soc., 38 [10] 908-13 (2001).

7. S. W. Lee, H. J. Kim, and E. H. Kim, "Control of Permanent Shrinking of Recycled Castable Refractories from Waste Refractories of $\mathrm{Al}_{2} \mathrm{O}_{3}-\mathrm{SiO}_{2}$ (in Korean)," J. Kor. Ceram. Soc., 29 [1] 15-22 (1992).

8. A. Kara and R. Stevens, "Characterisation of Biscuit Fired Bone China Body Microstructure. Part II : Transmission Electron Microscopy(TEM) of Glassy Matrix," J. Eur. Ceram. Soc., 22 [5] 737-43 (2002).

9. A. Kara and R. Stevens, "Interactions Between an ABS Type Leadless Glaze and a Biscuit Fired Bone China Body During Glost Firing. Part I: Preparation of Experimental Phases," J. Eur. Ceram. Soc., 22 [7] 1095-102 (2002).

10. A. Kara and R. Stevens, "Interactions Between an ABS Type Leadless Glaze and a Biscuit Fired Bone China Body During Glost Firing. Part II : Investigation of Interactions," $J$. Eur. Ceram. Soc., 22 [7] 1103-12 (2002).

11. A. Kara and R. Stevens, "Interactions Between an ABS Type Leadless Glaze and a Biscuit Fired Bone China Body During Glost Firing. Part III : Effect of Glassy Matrix Phase," $J$. Eur. Ceram. Soc., 23 [10] 1617-28 (2003).

12. J. I. Lee, Y. S. Lee, and B. H. Lee "Ceramics Body Development Using Waste Whiteware(in Korean)," J. Kor. Ceram. Soc., 43 [10] 626-34 (2006).

13. J. I. Lee, J. S. Park, Y. S. Lee, and B. H. Lee "Development of Ceramics Body using Waste Celadon(in Korean)," J. Kor. Ceram. Soc., 46 [6] 602-8 (2009). 